\title{
Inflorescences of Brassicacea species as source of bioactive compounds: A comparative study
}

\author{
Carla Sousa $^{\mathrm{a}}$, Marcos Taveira ${ }^{\mathrm{a}}$, Patrícia Valentão ${ }^{\mathrm{a}}$, Fátima Fernandes ${ }^{\mathrm{a}}$, José A. Pereira ${ }^{\mathrm{b}}$, Letícia Estevinho ${ }^{\mathrm{b}}$, \\ Albino Bento ${ }^{\mathrm{b}}$, Federico Ferreres ${ }^{\mathrm{c}}$, Rosa M. Seabra ${ }^{\mathrm{a}}$, Paula B. Andrade ${ }^{\mathrm{a}, *}$ \\ ${ }^{a}$ REQUIMTE/Serviço de Farmacognosia, Faculdade de Farmácia, Universidade do Porto, R. Aníbal Cunha, 164, 4050-047 Porto, Portugal \\ ${ }^{\mathrm{b}}$ CIMO/Escola Superior Agrária, Instituto Politécnico de Bragança, Campus de Sta Apolónia, Apartado 1172, 5301-855 Bragança, Portugal \\ ${ }^{\mathrm{c}}$ Research Group on Quality, Safety and Bioactivity of Plant Foods, Department of Food Science and Technology, CEBAS (CSIC), P.0. Box 164, 30100 Campus University Espinardo, \\ Murcia, Spain
}

\section{A R T I C L E I N F O}

Article history:

Received 22 October 2007

Received in revised form 28 December 2007

Accepted 29 February 2008

\section{Keywords:}

Brassica oleracea L. var. costata DC

Brassica oleracea L. var. acephala

Brassica rapa L. var. rapa

Inflorescences

Phenolic compounds

Organic acids

Antioxidant activity

Antimicrobial activity

\begin{abstract}
A B S T R A C T
Two Brassica oleracea varieties (B. oleracea L. var. costata DC and B. oleracea L. var. acephala) and Brassica rapa L. var. rapa inflorescences were studied for their chemical composition and antioxidant capacity. Phenolic compounds and organic acids profiles were determined by HPLC-DAD and HPLC-UV, respectively. B. oleracea var. costata and B. oleracea L. var. acephala inflorescences presented a similar qualitative phenolic composition, exhibiting several complex kaempferol derivatives and 3-p-coumaroylquinic acid, while $B$. rapa var. rapa was characterized by kaempferol and isorhamnetin glycosides and several phenolic acids derivatives. B. oleracea L. var. costata and B. rapa var. rapa showed the highest phenolics content. The three Brassica exhibited the same six organic acids (aconitic, citric, pyruvic, malic, shikimic and fumaric acids), but $B$. oleracea $\mathrm{L}$. var. acephala presented a considerably higher amount. Each inflorescence was investigated for its capacity to act as a scavenger of DPPH radical and reactive oxygen species (superoxide radical, hydroxyl radical and hypochlorous acid), exhibiting antioxidant capacity in a concentration dependent manner against all radicals. These samples were also studied for its antimicrobial potential against Gram-positive and Gram-negative bacteria and fungi, displaying antimicrobial capacity only against Gram-positive bacteria.
\end{abstract}

(c) 2008 Elsevier Ltd. All rights reserved.

\section{Introduction}

Brassica vegetables belong to the Cruciferous family, which includes a variety of economically significant horticultural crops. They are consumed all over the year as ingredients of different salads or after cooking of raw and frozen vegetables (Podsędek, 2007). Tronchuda cabbage (Brassica oleracea L. var. costata DC), kale (B. oleracea L. var. acephala DC) and turnip (Brassica rapa var. rapa L.) appear within the most consumed species.

Increasing attention has been paid to the role of diet in human health. In fact, food provides not only essential nutrients needed for life, but also other bioactive compounds for health promotion and disease prevention. It is generally assumed that the beneficial effects of vegetables are partly attributed to the complex mixture of phytochemicals possessing antioxidant activity (Liu, 2003; Podsędek, 2007). These comprise both phenolic compounds and organic acids (Liu, 2003; Podsędek, 2007; Pulido, Bravo, \& Saura-Calixto, 2000; Silva et al., 2004), which contribute to their organoleptic fea-

\footnotetext{
* Corresponding author. Tel.: +351 222078935; fax: +351 222003977

E-mail address: pandrade@ff.up.pt (P.B. Andrade).
}

tures (Vaughan \& Geissler, 1997), despite being applied in the quality control of several matrices (Fernandes et al., 2007; Ferreres et al., 2005; Sousa et al., 2005). Furthermore, plant compounds are known for their antimicrobial capacity (Cowan, 1999; Tim Cushnie \& Lamb, 2005), which may be relevant considering the existing problem of resistance to antimicrobial agents.

The polyphenol composition of several materials from members of Brassica genus, or their byproducts, has been described (Llorach, Gil-Izquierdo, Ferreres, \& Tomás-Barberán, 2003; Romani, Vignolini, Isolani, Ieri, \& Heimler, 2006; Vallejo, Tomás-Barberán, \& Ferreres, 2004), including that of B. oleracea var. costata (Ferreres et al., 2007, 2006, 2005; Sousa et al., 2005), B. oleracea var. acephala (Heimler, Vignolini, Dini, Vincieri, \& Romani, 2006; Romani et al., 2003) and B. rapa var. rapa (Fernandes et al., 2007; Liang et al., 2006), referring distinct profiles between them. Recent publications also report the organic acids (Ayaz et al., 2006; Fernandes et al., 2007; Ferreres et al., 2007, 2006; Sousa et al., 2005) and the antioxidant potential (Fernandes et al., 2007; Ferreres et al., 2007, 2006; Heimler et al., 2006; Vrchovská et al., 2006) of these three species. However, information regarding their inflorescences is almost non-existent. As far as we know, only one study about the phenolic compounds and organic acids composition of B. rapa var. 
rapa was performed by our group, suggesting that this constitutes an interesting dietary source of protective compounds, displaying a DPPH scavenging activity stronger than that of the roots and leaves (Fernandes et al., 2007).

The objectives of this study were to define and compare the phenolics and organic acids composition and the biological potentials of the inflorescence of three Brassica varieties: B. oleracea var. costata, B. oleracea var. acephala and B. rapa var. rapa. For these purposes, the phenolic profile was established by reversed-phase HPLC-DAD analysis, while organic acids were determined by HPLC-UV. The antioxidant capacity was assessed by scavenging assays against DPPH radical and reactive oxygen species (superoxide radical, hydroxyl radical and hypochlorous acid). The antimicrobial potential was checked for three Gram-positive (Bacillus cereus, $B$. subtilis and Staphylococus aureus) and three Gram-negative bacteria (Escherichia coli, Pseudomonas aeruginosa and Klebsiella pneumoniae) and two fungi species (Candida albicans and Cryptococcus neoformans).

\section{Materials and methods}

\subsection{Standards and reagents}

Malic, shikimic, fumaric, caffeic, $p$-coumaric acids were purchased from Sigma (St. Louis, MO, USA). Aconitic, citric, pyruvic, ferulic and sinapic acids, kaempferol 3-O-rutinoside and isorhamnetin 3-O-glucoside were from Extrasynthése (Genay, France). Methanol, formic and acetic acids were obtained from Merck (Darmstadt, Germany) and sulphuric acid from Pronalab (Lisboa, Portugal). The water was treated in a Milli-Q water purification system (Millipore, Bedford, MA, USA). DPPH, xanthine, xanthine oxidase (XO) grade I from buttermilk (EC 1.1.3.22), $\beta$-nicotinamide adenine dinucleotide (NADH), phenazine methosulfate (PMS), nitroblue tetrazolium chloride (NBT), ferric chloride anhydrous $\left(\mathrm{FeCl}_{3}\right)$, ethylenediaminetetraacetic acid disodium salt (EDTA), ascorbic acid, trichloroacetic acid, thiobarbituric acid, deoxyribose, sodium hypochlorite solution with $4 \%$ available chlorine $(\mathrm{NaOCl})$, 5,5'-dithiobis(2-nitrobenzoic acid) (DTNB) were obtained from Sigma Chemical Co. (St. Louis, USA).

\subsection{Samples}

Inflorescences of B. oleracea L. var. costata DC, B. oleracea L. var. acephala and B. rapa L. var. rapa were collected in Carrazeda de Ansiães, Northeast Portugal, in February 2006. After harvesting, the material of three distinct individuals of each variety was immediately transferred to the laboratory and frozen at $-20^{\circ} \mathrm{C}$, prior to their lyophilisation in a Labconco 4.5 Freezone apparatus (Kansas City, MO, USA). Then the dried material was powdered, mixed and stored in a desiccator, in the dark.

\subsection{Sample preparation}

An aqueous extract was used for the phytochemical characterization and in the biological activities assays: ca. $3.0 \mathrm{~g}$ of powdered inflorescences were boiled for $15 \mathrm{~min}$ in $600 \mathrm{ml}$ water and then filtered over a Büchner funnel. The resulting extract was lyophilized in a Labconco 4.5 Freezone apparatus (Kansas City, MO, USA) and yields of ca. $1.2 \mathrm{~g}$ (B. oleracea $\mathrm{L}$. var. costata $\mathrm{DC}), 1.2 \mathrm{~g}$ (B. rapa $\mathrm{L}$. var. rapa), and $0.8 \mathrm{~g}$ (B. oleracea $\mathrm{L}$. var. acephala) were obtained. The lyophilized extracts were kept in a desiccator, in the dark.

For the characterization and quantification of the phenolic compounds by HPLC-DAD, each lyophilized extract was redissolved in water. For organic acids determination they were redissolved in sulphuric acid $0.01 \mathrm{~N}$ prior to analysis by HPLC-UV.

\subsection{HPLC-DAD analysis of phenolic compounds}

Twenty microliters of inflorescences lyophilized extracts were analyzed using a HPLC unit (Gilson) and a Spherisorb ODS2 $(25.0 \times 0.46 \mathrm{~cm} ; 5 \mu \mathrm{m}$, particle size $)$ column. The $B$. oleracea varieties (costata and acephala) were analyzed as previously described (Ferreres et al., 2005), using a mixture of formic acid 5\% (A) and methanol (B), with a flow rate of $1 \mathrm{ml} / \mathrm{min}$, as follows: $0 \mathrm{~min}-$ $10 \%$ B, 25 min - 20\% B, 40 min - 50\% B, 45 min - 50\% B, 46 min $90 \%$ B, 50 min - 90\% B, 55 min - 100\% B, $58 \min -100 \%$ B, $60 \mathrm{~min}-10 \% \mathrm{~B}$.

The separation of $B$. rapa var. rapa phenolic compounds was achieved as before (Fernandes et al., 2007), with a solvent mixture of water (adjusted to $\mathrm{pH} 3.2$ with formic acid at $10 \%, \mathrm{v} / \mathrm{v}$ ) (A) and methanol (B). Elution was carried out at $1 \mathrm{ml} / \mathrm{min}$ and followed the gradient system $20 \% \mathrm{~B}$ at $0 \mathrm{~min}, 50 \%$ B at $35 \mathrm{~min}, 80 \% \mathrm{~B}$ at $45 \mathrm{~min}$ and $100 \% \mathrm{~B}$ at $50 \mathrm{~min}$. Detection was achieved with a Gilson diode array detector. Spectral data from all peaks were accumulated in the range of $200-400 \mathrm{~nm}$, and chromatograms were recorded at $330 \mathrm{~nm}$. The data were processed on Unipoint system Software (Gilson Medical Electronics, Villiers le Bel, France). Peak purity was checked by the software contrast facilities.

Phenolic compounds quantification was achieved by the absorbance recorded in the chromatograms relative to external standards. Since standards of several compounds identified in the lyophilized extracts were not commercially available, 3-p-coumaroylquinic acid was quantified as $p$-coumaric acid, and sinapic acid, kaempferol and isorhamnetin derivatives as sinapic acid, kaempferol 3-O-rutinoside and isorhamnetin 3-O-glucoside, respectively. The other compounds were quantified as themselves.

\subsection{HPLC-UV analysis of organic acids}

The separation of the organic acids present in the inflorescences lyophilized extracts was carried out as previously reported (Sousa et al., 2005), in a system consisting of an analytical HPLC unit (Gilson) with an ion exclusion column, Nucleogel ${ }^{\circledR}$ Ion 300 OA $(300 \times 7.7 \mathrm{~mm})$ in conjunction with a column heating device set at $30^{\circ} \mathrm{C}$. Briefly, elution was carried out isocratically, at a solvent flow rate of $0.2 \mathrm{ml} / \mathrm{min}$, with sulphuric acid $0.01 \mathrm{~N}$. The detection was performed with an UV detector set at $214 \mathrm{~nm}$.

Organic acids quantification was achieved by the absorbance recorded in the chromatograms relative to external standards.

\section{6. $D P P H *$ scavenging activity}

The antiradical activity of the extracts was determined spectrophotometrically in a Multiscan Ascent plate reader (Thermo Electron Corporation), by monitoring the disappearance of $\mathrm{DPPH}^{\cdot}$ at $515 \mathrm{~nm}$, according to a described procedure (Ferreres et al., 2006; Vrchovská et al., 2006). For each extract, a dilution series composed of five different concentrations was prepared in a 96 well plate. The reaction mixtures in the sample wells consisted of $25 \mu \mathrm{l}$ aqueous extract and $200 \mu \mathrm{l}$ of $150 \mu \mathrm{M} \mathrm{DPPH}^{\cdot}$ dissolved in methanol. The plate was incubated for $30 \mathrm{~min}$ at room temperature. Three experiments were performed in triplicate.

\subsection{Superoxide radical-scavenging activity}

Antiradical activity of the aqueous extracts was determined spectrophotometrically in a Multiscan Ascent plate reader (Thermo Electron Corporation), by monitoring at $562 \mathrm{~nm}$ the formation of formazan as a result of the superoxide radical-induced reduction of NBT. 


\subsubsection{Non-enzymatic assay}

Superoxide radicals were generated by the NADH/PMS system according to a described procedure (Valentão et al., 2001). All components were dissolved in phosphate buffer (19 mM, pH 7.4). Experiments were performed in triplicate.

\subsubsection{Enzymatic assay}

Superoxide radicals were generated by the xanthine/xanthine oxidase $(\mathrm{X} / \mathrm{XO})$ system following as reported before (Valentão et al., 2001). Briefly, xanthine was dissolved in $\mathrm{NaOH}(1 \mu \mathrm{M})$ and subsequently in phosphate buffer $(50 \mathrm{mM})$ with EDTA $(0.1 \mathrm{mM}$, $\mathrm{pH} 7.8)$, xanthine oxidase in EDTA $(0.1 \mathrm{mM})$ and the remaining components in phosphate buffer $(50 \mathrm{mM})$ with EDTA $(0.1 \mathrm{mM}$, $\mathrm{pH}$ 7.8). Experiments were performed in triplicate.

\subsubsection{Effect on xanthine oxidase activity}

The effect of the lyophilized extracts on xanthine oxidase activity was evaluated by measuring the formation of uric acid from xanthine in a double beam spectrophotometer (He $\lambda$ ios $\alpha$, Unicam), at room temperature, according to a described procedure (Valentão et al., 2001). The reaction mixtures contained the same proportion of components as in the enzymatic assay for superoxide radicalscavenging activity, except NBT, in a final volume of $750 \mu$ l. The absorbance was measured at $295 \mathrm{~nm}$ for $2 \mathrm{~min}$. Experiments were performed in triplicate.

\subsection{Hydroxyl radical assay}

The deoxyribose method for determining the scavenging effect of the aqueous extracts on hydroxyl radicals was performed as previously described (Valentão et al., 2002) in a double beam spectrophotometer (He $\lambda$ ios $\alpha$, Unicam). Reaction mixtures contained $50 \mu \mathrm{M}$ ascorbic acid, $40 \mu \mathrm{M} \mathrm{FeCl}, 2 \mathrm{mM}$ EDTA, $2.8 \mathrm{mM}$ $\mathrm{H}_{2} \mathrm{O}_{2}, 2.8 \mathrm{mM}$ deoxyribose and lyophilized extracts. All components were dissolved in $\mathrm{KH}_{2} \mathrm{PO}_{4}-\mathrm{KOH}$ buffer $10 \mathrm{mM}, \mathrm{pH}$ 7.4. This assay was also performed either without ascorbic acid or EDTA, in order to evaluate the extracts pro-oxidant and metal chelation potential, respectively. Experiments were performed in triplicate.

\subsection{Hypochlorous acid scavenging activity}

The inhibition of hypochlorous acid-induced 5-thio-2-nitrobenzoic acid (TNB) oxidation to 5,5'-dithiobis(2-nitrobenzoic acid) was performed according to a described procedure (Valentão et al., 2002), in a double beam spectrophotometer (He $\lambda$ ios $\alpha$, Unicam). Hypochlorous acid and TNB were prepared immediately before use. Experiments were performed in triplicate.

\subsection{Antimicrobial activity}

\subsubsection{Microorganisms and culture conditions}

Microorganisms CECT were obtained from the Spanish type culture collection (CECT) of Valencia University, while microorganisms ESA were clinically isolated strains identified in the Microbiology Laboratory of Escola Superior Agrária de Bragança. Gram-positive (B. cereus CECT 148, B. subtilis CECT 498 and S. aureus ESA 7 isolated from pus) and Gram-negative (E. coli CECT 101, $P$. aeruginosa CECT 108 and $K$. pneumoniae ESA 8 isolated from urine) bacteria, and fungi (C. albicans CECT 1394 and C. neoformans ESA 3 isolated from vaginal fluid) were used to screen the antimicrobial potential of the three Brassica varieties. Microorganisms were cultured aerobically at $37^{\circ} \mathrm{C}$ (Scientific 222 oven) in nutrient agar medium for bacteria, and at $30^{\circ} \mathrm{C}$ (Scientific 222 oven) in Sabouraud dextrose agar medium for fungi.

\subsubsection{Assay}

The screening of antibacterial activities against Gram-positive and Gram-negative bacteria and fungi and the determination of the minimal inhibitory concentration (MIC) were achieved by an adaptation of the agar streak dilution method based on radial diffusion, as previously reported (Hawkey \& Lewis, 1994; Pereira et al., 2006; Sousa et al., 2006). Suspensions of the microorganism were prepared to contain approximately $108 \mathrm{cfu} / \mathrm{ml}$, and the plates containing agar medium were inoculated $(100 \mu \mathrm{l}$; spread on the surface). Each sample $(50 \mu \mathrm{l})$ was placed in a hole $(3 \mathrm{~mm}$ depth, $4 \mathrm{~mm}$ diameter) made in the centre of the agar. The MIC was considered to be the lowest concentration of the tested sample able to inhibit the growth of bacteria or fungi, after 24 and $48 \mathrm{~h}$, respectively. The diameters of the inhibition zones corresponding to the MICs were measured using a ruler, with an accuracy of $0.5 \mathrm{~mm}$. Each inhibition zone diameter was measured three times (three different plates) and the average was considered. A control using only inoculation was also carried out.

\section{Results and discussion}

\subsection{Phenolic composition of the inflorescences}

The HPLC-DAD analysis allowed the identification of fourteen phenolic compounds in the inflorescences of $B$. oleracea var. costata: 3-p-coumaroylquinic acid, kaempferol 3-O-sophorotrioside-7$O$-glucoside, kaempferol 3-O-(methoxycaffeoyl/caffeoyl)-sophoroside-7-O-glucoside, kaempferol 3-O-sophoroside-7-O-glucoside, kaempferol 3-O-sophorotrioside-7-O-sophoroside, kaempferol 3$O$-sophoroside-7-O-sophoroside, kaempferol 3-O-tetraglucoside7-O-sophoroside, kaempferol 3-O-(sinapoyl/caffeoyl)-sophoroside-7-O-glucoside, kaempferol 3-O-(feruloyl/caffeoyl)-sophoroside-7-O-glucoside, kaempferol 3-O-sophorotrioside, kaempferol 3-O-(sinapoyl)-sophoroside, kaempferol 3-O-(feruloyl)-sophorotrioside, kaempferol 3-O-(feruloyl)-sophoroside and kaempferol 3-Osophoroside (Fig. 1A). All these compounds have been previously described in B. oleracea var. costata leaves (Ferreres et al., 2006, 2005; Sousa et al., 2005).

The same compounds were found in B. oleracea var. acephala inflorescences aqueous lyophilized extract (Fig. 1B), with the exception of kaempferol 3-O-tetraglucoside-7-O-sophoroside (compound 7). Among the detected phenolics, only kaempferol 3-O-sophoroside-7-O-glucoside has been reported in the leaves of this B. oleracea variety (Romani et al., 2003).

B. rapa var. rapa inflorescences exhibited several phenolic acids and flavonoids distinct from those found in the B. oleracea varieties, namely isorhamnetin derivatives. Besides 3-p-coumaroylquinic acid, kaempferol 3-O-sophoroside-7-O-glucoside, kaempferol 3-Osophoroside-7-O-sophoroside, kaempferol 3-O-(feruloyl/caffeoyl)sophoroside-7-O-glucoside and kaempferol 3-O-sophoroside detected in the above mentioned varieties, also identified were caffeic, ferulic and sinapic acids, kaempferol 3,7-O-diglucoside, isorhamnetin 3,7-O-diglucoside, 1,2-disinapoylgentiobiose, 1,2'disinapoyl-2-feruloylgentiobiose, kaempferol 3-O-glucoside and isorhamnetin 3-O-glucoside (Fig. 2). These compounds have been already described in $B$. rapa var. rapa leaves and inflorescences (Fernandes et al., 2007). In addition, as observed before with other materials, isorhamnetin derivatives are present in B. rapa group and absent in B. oleracea (Romani et al., 2006).

The quantification of the identified phenolics in the three analyzed Brassica varieties inflorescences revealed that $B$. oleracea var. costata and B. rapa var. rapa present the highest contents (ca. 20 and $18 \mathrm{~g} / \mathrm{kg}$, respectively), corresponding to twice more the amount exhibited by B. oleracea var. acephala (ca. $9 \mathrm{~g} / \mathrm{kg}$ ) (Tables 1 and 2). 

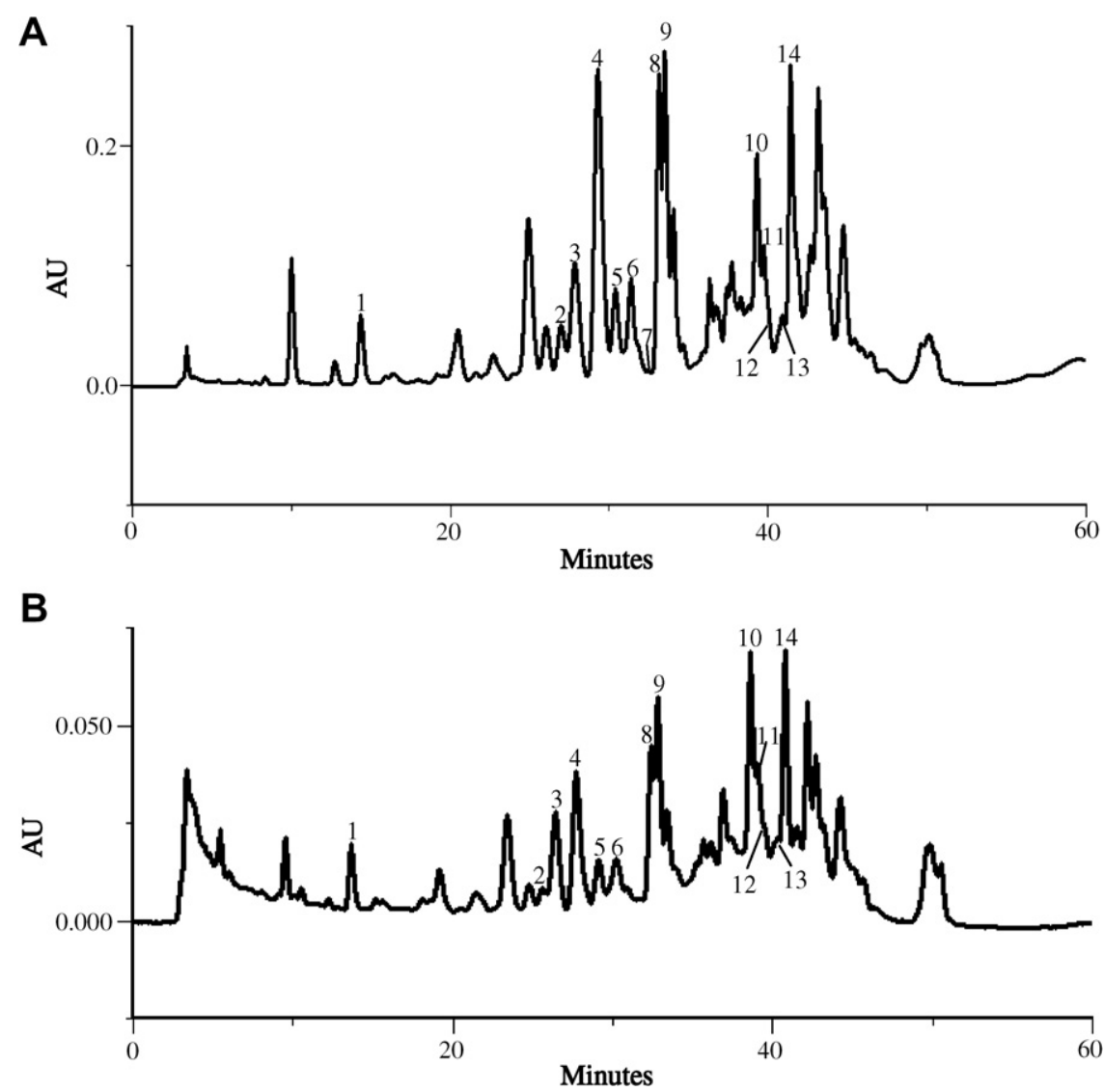

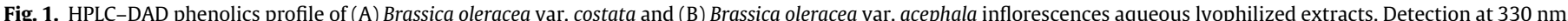

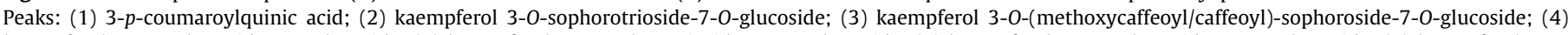

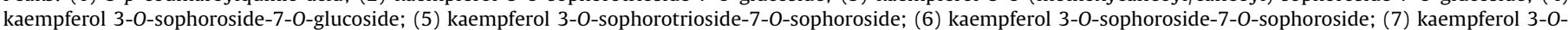

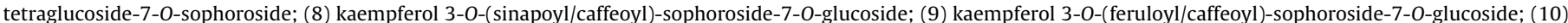

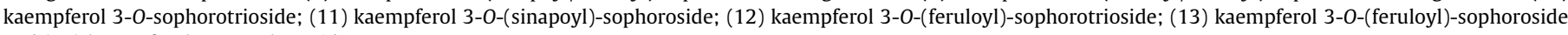
and (14) kaempferol 3-O-sophoroside.

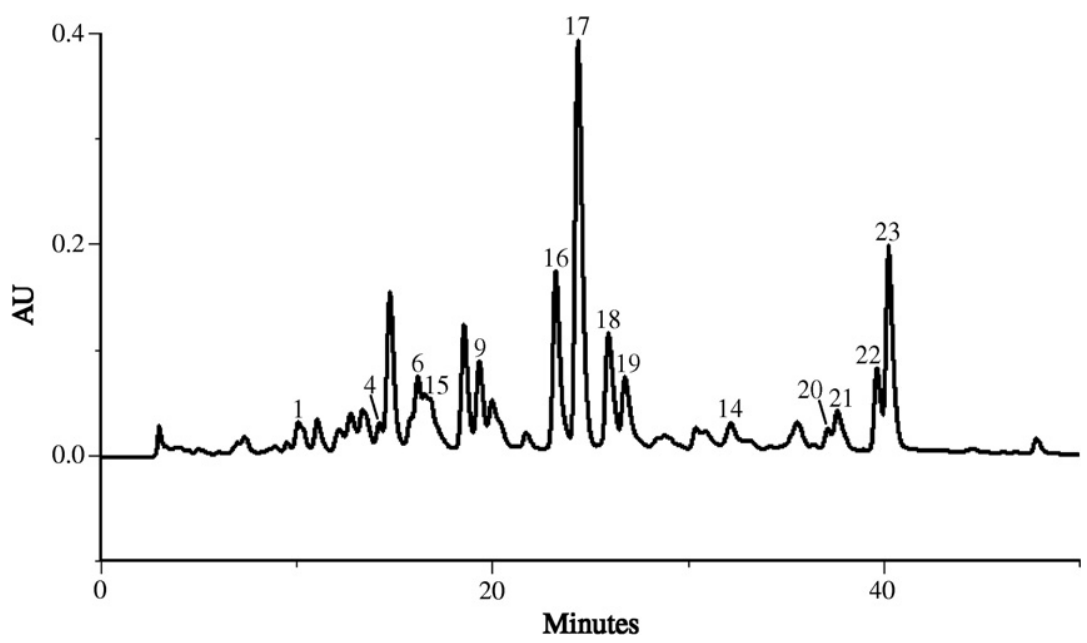

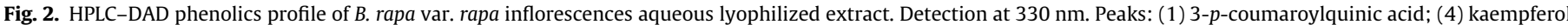

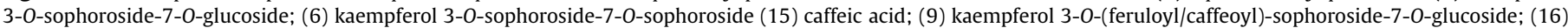

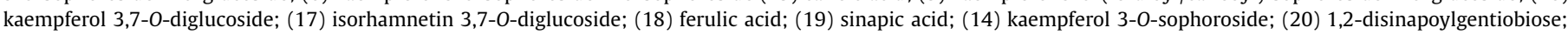
(21) 1,2'-disinapoyl-2-feruloylgentiobiose; (22) kaempferol 3-O-glucoside and (23) isorhamnetin 3-O-glucoside.

Despite their similar qualitative composition, the two $B$. oleracea varieties showed distinct profiles. In B. oleracea var. costata inflorescences kaempferol 3-O-sophoroside-7-O-glucoside is the main compound (corresponding to ca. $19 \%$ of total phenolics) and kaempferol 3-O-tetraglucoside-7-O-sophoroside the minor one (less than $0.5 \%$ ), while in B. oleracea var. acephala kaempferol 3$O$-sophoroside is the compound present in highest amounts (representing ca. $21 \%$ of total phenolics) and 3-p-coumaroylquinic acid 
Table 1

Quantification of phenolic compounds in Brassica oleracea varieties' inflorescences

\begin{tabular}{|c|c|c|c|}
\hline \multirow[t]{2}{*}{ 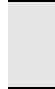 } & \multirow[t]{2}{*}{ Compound } & \multicolumn{2}{|c|}{$\mathrm{mg} / \mathrm{kg}\left(\right.$ dry basis) ${ }^{\mathrm{a}}$} \\
\hline & & var. costata & var. acephala \\
\hline 1 & 3- $p$-Coumaroyl quinic acid & $305.1 \pm 2.9$ & $165.6 \pm 2.5$ \\
\hline 2 & Kaempferol 3-O-sophtr-7-O-gluc & $630.8 \pm 4.4$ & $172.8 \pm 9.5$ \\
\hline 3 & $\begin{array}{l}\text { Kaempferol 3-O- (methoxycaffeoyl/ } \\
\text { caffeoyl)-soph-7-O-gluc }\end{array}$ & $1508.7 \pm 4.9$ & $783.2 \pm 32.0$ \\
\hline 4 & Kaempferol 3-O-soph-7-O-gluc & $3678.1 \pm 10.0$ & $839.5 \pm 37.4$ \\
\hline 5 & Kaempferol 3-O-sophtr-7-O-soph & $989.5 \pm 5.3$ & $308.7 \pm 3.7$ \\
\hline 6 & Kaempferol 3-O-soph-7-O-soph & $1263.2 \pm 3.5$ & $426.8 \pm 12.5$ \\
\hline 7 & Kaempferol 3-O-tetragluc-7-O-soph & $78.4 \pm 1.2$ & nd \\
\hline 8 & $\begin{array}{l}\text { Kaempferol 3-O-(sinapoyl/caffeoyl)-soph-7- } \\
\text { O-gluc }\end{array}$ & $1809.0 \pm 40.3$ & $663.9 \pm 67.0$ \\
\hline 9 & $\begin{array}{l}\text { Kaempferol 3-O- (feruloyl/caffeoyl)-soph-7- } \\
\text { O-gluc }\end{array}$ & $2322.1 \pm 19.1$ & $1055.5 \pm 66.7$ \\
\hline 10 & Kaempferol 3-O-sophtr & $1783.8 \pm 9.9$ & $1353.5 \pm 18.0$ \\
\hline 11 & Kaempferol 3-O-(sinapoyl)-soph & $1345.3 \pm 3.8$ & $1148.9 \pm 58.4$ \\
\hline 12 & Kaempferol 3-O-(feruloyl)-sophtr & & \\
\hline 13 & Kaempferol 3-O-(feruloyl)-soph & $760.2 \pm 1.1$ & $533.1 \pm 42.0$ \\
\hline \multirow[t]{2}{*}{14} & Kaempferol 3-O-soph & $3093.6 \pm 3.5$ & $2003.9 \pm 121.6$ \\
\hline & $\sum$ & 19567.7 & 9455.4 \\
\hline
\end{tabular}

a Results are expressed as mean \pm standard deviation of three determinations. $\sum$ sum of the determined phenolic compounds. nd: not detected. sophtr: sophorotriose; soph: sophorose; gluc: glucose.

and kaempferol 3-O-sophorotrioside-7-O-glucoside are the less abundant, each one corresponding to ca. $2 \%$. In these varieties the phenolic acids contribution is very small, ca. $2 \%$ of total phenolics in each variety, being clearly distinct from the ca. $26 \%$ exhibited by the inflorescences of $B$. rapa var. rapa (Tables 1 and 2). In this latter species, isorhamnetin 3,7-O-diglucoside is the major compound, accounting for $19 \%$ of total phenolics, and $1,2^{\prime}$-disinapoyl-2-feruloylgentiobiose is the one present in lowest amounts (ca. $1 \%$ ).

\subsection{Organic acids in the inflorescences}

An identical qualitative profile was found for the three analyzed Brassica varieties, which was composed by six organic acids: aco-
Table 2

Quantification of phenolic compounds in Brassica rapa var. rapa inflorescences

\begin{tabular}{lll}
\hline & Compound & $\mathrm{mg} / \mathrm{kg}$ (dry basis) \\
\hline 1 & 3-p-Coumaroyl quinic acid & $1084.8 \pm 10.5$ \\
4 & Kaempferol 3-O-soph-7-O-gluc & $479.8 \pm 24.4$ \\
6 & Kaempferol 3-O-soph-7-O-soph & $2098.5 \pm 82.7$ \\
15 & Caffeic acid & $422.2 \pm 10.5$ \\
9 & Kaempferol 3-O-(feruloyl/caffeoyl)-soph-7-O-gluc & $2109.7 \pm 165.4$ \\
16 & Kaempferol 3,7-O-digluc & $1208.9 \pm 94.8$ \\
17 & Isorhamnetin 3,7-O-digluc & $3483.8 \pm 23.1$ \\
18 & Ferulic acid & $2189.8 \pm 58.3$ \\
19 & Sinapic acid & $790.4 \pm 7.8$ \\
14 & Kaempferol 3-O-soph & $2127.8 \pm 97.9$ \\
20 & 1,2-Disinapoyl-gentiobiose & $136.3 \pm 14.1$ \\
21 & 1,2'-Disinapoyl-2-feruloyl-gentiobiose & $103.3 \pm 2.3$ \\
22 & Kaempferol 3-O-gluc & $734.0 \pm 18.7$ \\
23 & Isorhamnetin 3-O-gluc & $1414.3 \pm 8.3$ \\
& $\sum$ & 18383.8
\end{tabular}

a Results are expressed as mean \pm standard deviation of three determinations. $\sum$ sum of the determined phenolic compounds; nd: not detected; soph: sophorose and gluc: glucose

nitic, citric, pyruvic, malic, shikimic and fumaric acids (Fig. 3). All these compounds were already described to occur in both $B$. oleracea var. costata (Ferreres et al., 2007, 2006; Sousa et al., 2005) and B. rapa var. rapa (Fernandes et al., 2007), with the exception of pyruvic acid that is identified for the first time in these varieties. Additionally, ascorbic acid that was present in leaves and seeds of B. oleracea var. costata (Ferreres et al., 2007, 2006; Sousa et al., 2005) was not detected in its inflorescences. Regarding $B$. oleracea var. acephala, only citric and malic acids were previously reported in the leaves (Ayaz et al., 2006).

From a quantitative point of view, B. oleracea var. acephala inflorescences showed the highest organic acids content (ca. $163 \mathrm{~g} /$ $\mathrm{kg}$ ), corresponding to about three and four times the amount found for those of costata variety and B. rapa var. rapa, respectively (Table 3). B. oleracea var. costata exhibited a profile in which citric acid was the main compound (ca. $57 \%$ of total organic acids) and shikimic acid the minor one (less than $0.5 \%$ ). In B. oleracea var. acephala and B. rapa var. rapa malic acid was the major organic acid, corre-

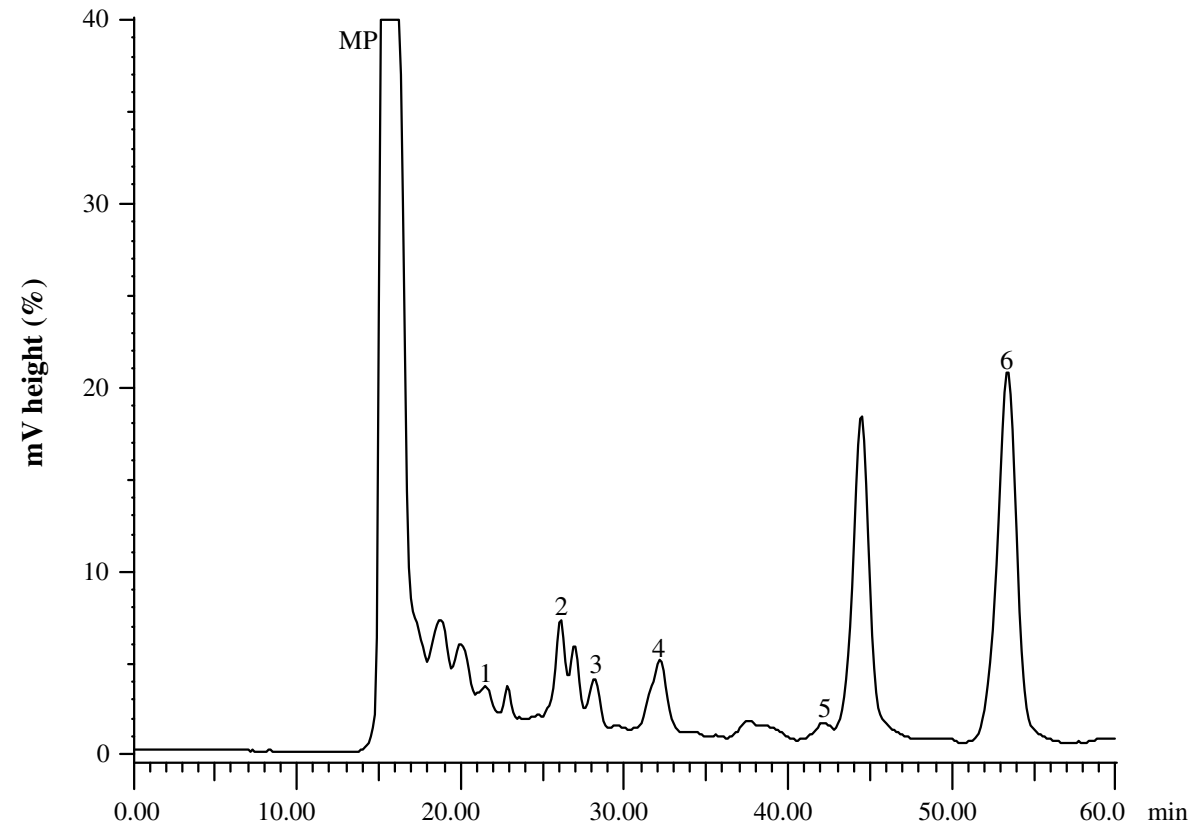

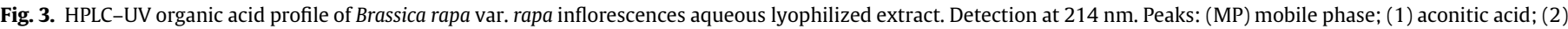
citric acid; (3) pyruvic acid; (4) malic acid; (5) shikimic acid and (6) fumaric acid. 
Table 3

Quantification of organic acids in Brassica inflorescences ( $\mathrm{mg} / \mathrm{kg}$, dry basis) ${ }^{\mathrm{a}}$

\begin{tabular}{lccr}
\hline Compound & $\begin{array}{l}\text { B. oleracea } \\
\text { var. costata }\end{array}$ & $\begin{array}{l}\text { B. oleracea } \\
\text { var. acephala }\end{array}$ & $\begin{array}{l}\text { B. rapa } \\
\text { var. rapa }\end{array}$ \\
\hline Aconitic acid & $426.7 \pm 7.7$ & $97.0 \pm 2.6$ & $42.3 \pm 0.2$ \\
Citric acid & $27925.7 \pm 166.9$ & $48373.3 \pm 1846.1$ & $13177.3 \pm 75.4$ \\
Pyruvic acid & $2684.0 \pm 5.6$ & $5686.7 \pm 77.3$ & $1123.2 \pm 1.0$ \\
Malic acid & $16734.2 \pm 78.9$ & $108158.7 \pm 445.9$ & $22349.6 \pm 2.1$ \\
Shikimic acid & $137.4 \pm 0.6$ & $764.7 \pm 6.4$ & $68.7 \pm 0.8$ \\
Fumaric acid & $1115.9 \pm 4.4$ & $17.5 \pm 0.3$ & $1260.8 \pm 2.0$ \\
$\sum$ & 49023.9 & 163097.9 & 38022.0 \\
\hline
\end{tabular}

a Results are expressed as mean \pm standard deviation of three determinations. $\sum$, sum of the determined organic acids.

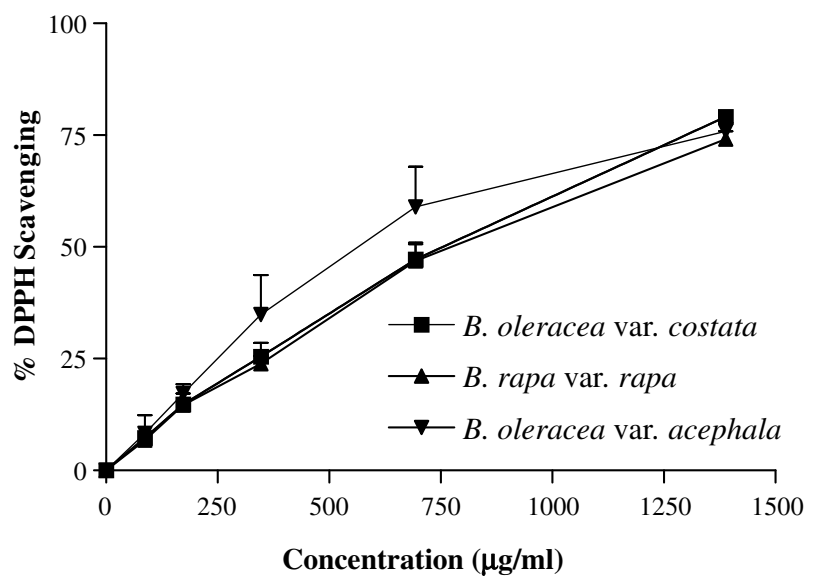

Fig. 4. Effect of inflorescences aqueous lyophilized extracts on DPPH' reduction. Values show mean \pm SE from three experiments performed in triplicate.

Table 4

Antioxidant activity of the inflorescences' aqueous extracts $(\mu \mathrm{g} / \mathrm{ml})$

\begin{tabular}{llcc}
\hline Assay & $\begin{array}{l}\text { B. oleracea } \\
\text { var. costata }\end{array}$ & $\begin{array}{l}\text { B. oleracea } \\
\text { var. acephala }\end{array}$ & $\begin{array}{l}\text { B. rapa } \\
\text { var. rapa }\end{array}$ \\
\hline DPPH $^{\mathrm{a}}$ & 754 & 565 & 774 \\
Superoxide radical (X/XO) $^{\mathrm{b}}$ & 507 & 405 & 244 \\
Superoxide radical (NADH/PMS) $^{\mathrm{b}}$ & 349 & 281 & 363 \\
Hydroxyl radical $^{\mathrm{b}}$ & 172 & 10 & 12 \\
HOCl $^{\mathrm{c}}$ & 639 & 1186 & 770 \\
\hline
\end{tabular}

a Data correspond to $\mathrm{IC}_{50}$ values.

b Data correspond to $\mathrm{IC}_{25}$ values.

c Data correspond to $\mathrm{IC}_{10}$ values.

sponding to ca. 66 and 59\% of total compounds, respectively. In both cases aconitic acid was the compound present in lowest amount, representing ca. $0.1 \%$ of total acids. Despite this coincidence, it can be noticed that, comparing with B. oleracea var. acephala, $B$. rapa var. rapa has a higher relative content of citric acid. On the other hand, its malic acid amount is inferior to that of $B$. oleracea var. acephala. Nevertheless, and according to the obtained results, it is evident that both citric and malic acids are the most important compounds: the sum of their amounts in the three analyzed Brassica inflorescences varies between ca. $91 \%$ and $94 \%$ of total organic acids (Table 3 ).

\subsection{Antioxidant activity}

The Brassica inflorescences were screened by the DPPH' assay, which provides basic information about their capacity to scavenge free radicals. In this assay the three varieties displayed a concen- tration dependent antioxidant potential. B. oleracea var. acephala was revealed to have a stronger capacity than $B$. oleracea var. costata and B. rapa var. rapa, which exhibited a similar behavior (Fig. 4, Table 4).

The three varieties exhibited a concentration dependent superoxide radical-scavenging activity, using the enzymatic system, and B. rapa var. rapa was the most effective one (Fig. 5A, Table 4). The effect of the aqueous lyophilized extracts on XO activity was also checked; once in this assay the inhibitory effect on the enzyme itself could also lead to a decrease of NBT reduction (Valentão et al., 2001). Thus, a control experiment monitoring the metabolic conversion of xanthine to uric acid was performed, revealing that for
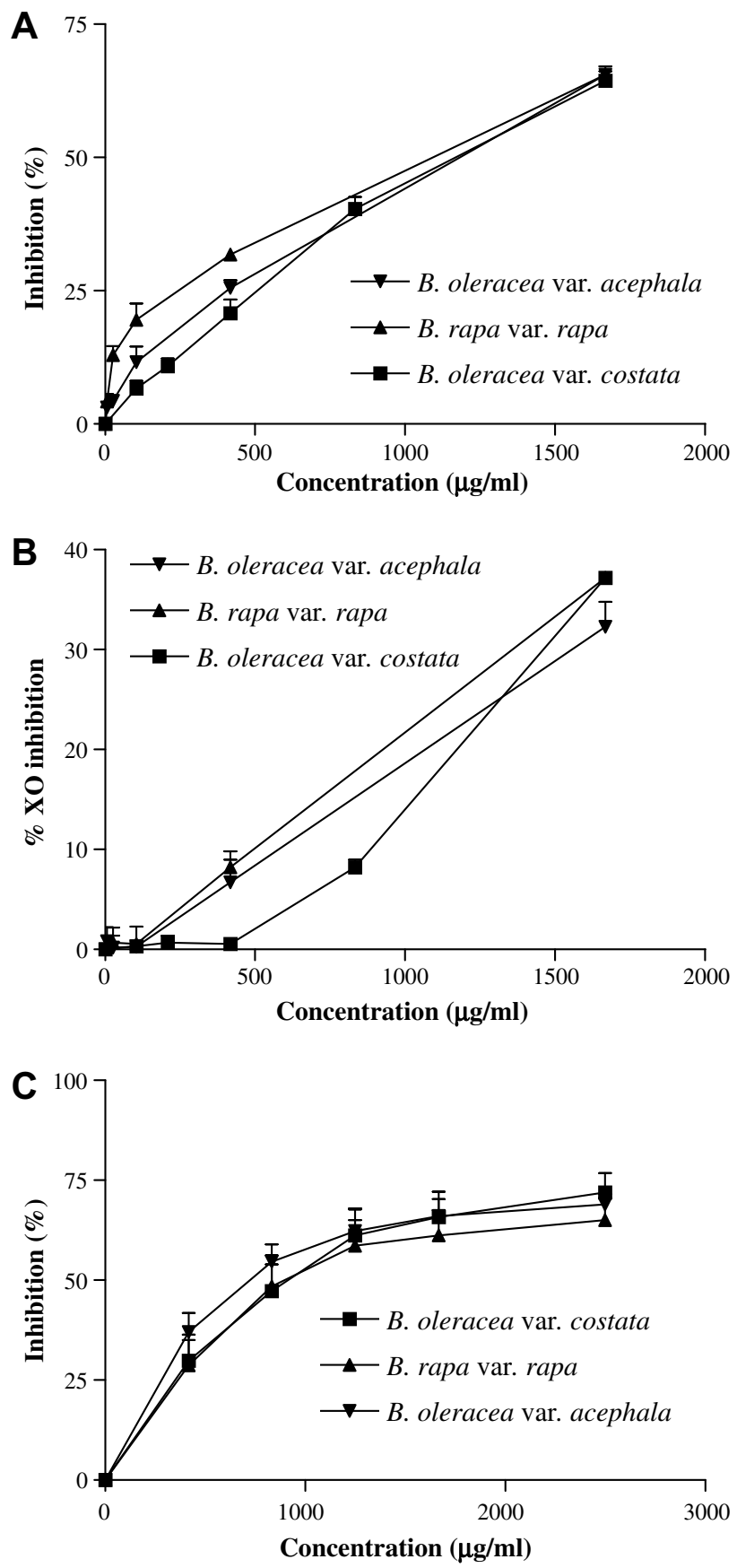

Fig. 5. Effect of inflorescences aqueous lyophilized extracts against superoxide $r$ adical generated in $\mathrm{X} / \mathrm{XO}$ system (A), on XO activity (B), and against superoxide radical generated in NADH/PMS system (C). Values show mean \pm SE from three experiments performed in triplicate. 
concentrations above $104 \mu \mathrm{g} / \mathrm{ml}$ both B. oleracea var. acephala and $B$. rapa var. rapa have $\mathrm{XO}$ inhibitory capacity. B. oleracea var. costata was also able to inhibit this enzyme, but only for concentrations higher than $417 \mu \mathrm{g} / \mathrm{ml}$ (Fig. 5B). Considering these results it was not possible to show a clear-cut scavenging effect on superoxide radical. To confirm the scavenging capacity we also determined the effect of the extracts on superoxide radical generated in a chemical system, and a concentration dependent effect was observed, with $B$. oleracea var. acephala displaying the stronger capacity (Fig. 5C, Table 4).
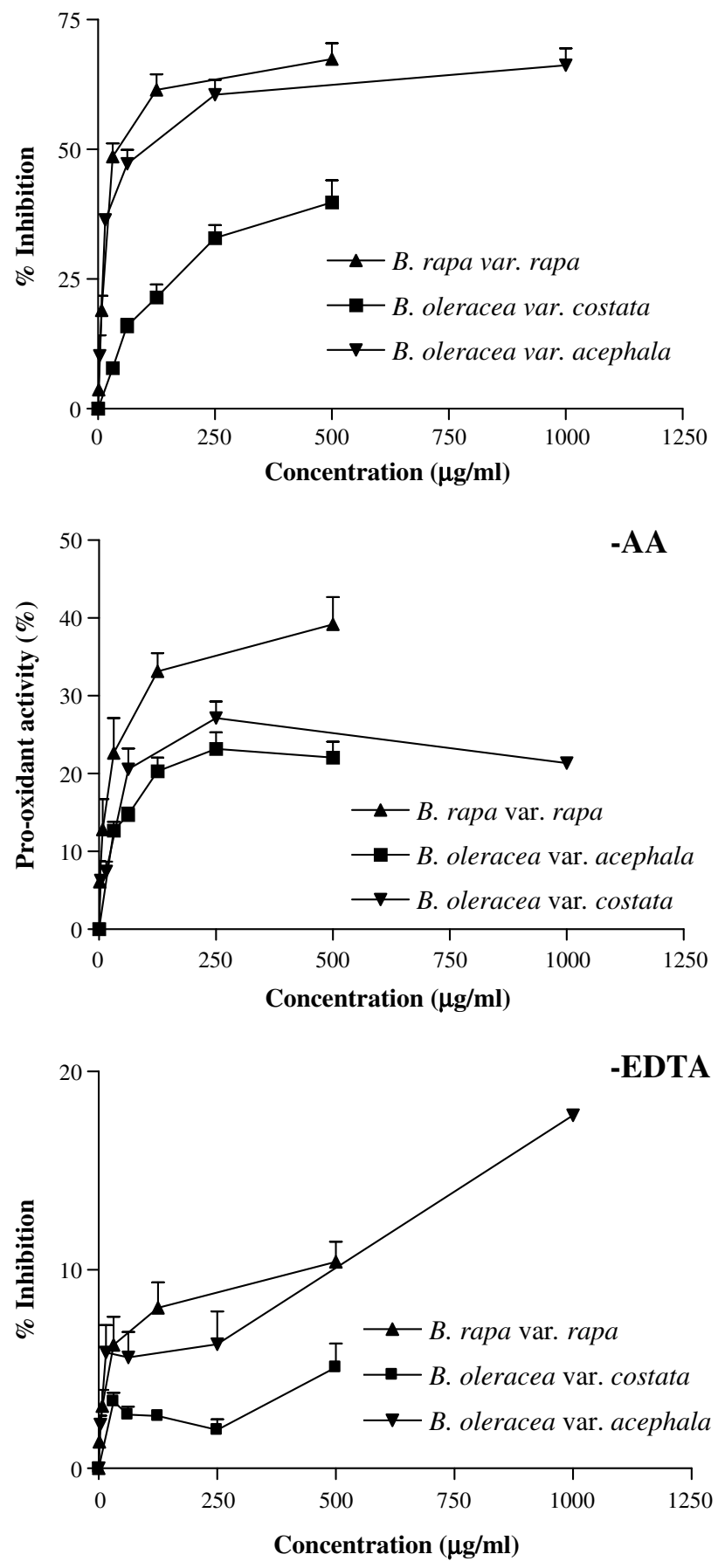

Fig. 6. Inflorescences aqueous lyophilized extracts non-specific hydroxyl radicalscavenging activity, pro-oxidant activity (-AA) and specific hydroxyl radical-scavenging (-EDTA). Values show mean \pm SE from three experiments performed in triplicate.
B. oleracea var. acephala and B. rapa var. rapa lyophilized extracts also exhibited a similar potent scavenging activity for hydroxyl radical, in a concentration dependent manner, which was more pronounced than that of $B$. oleracea var. costata (Fig. 6, Table 4). If we omit ascorbate from the reaction mixture, and if pro-oxidant compounds are present, they will be able to redox cycle the metal ion required for hydroxyl generation, thus increasing the radical production (Valentão et al., 2002). In order to evaluate the pro-oxidant potential of the three inflorescences, we omitted ascorbic acid, and we found that they were effective substitutes for ascorbate, although $B$. oleracea var. costata presented pro-oxidant capacity only for concentrations below $250 \mu \mathrm{g} / \mathrm{ml}$ (Fig. 6). So, it seems that, at the tested concentrations, the three inflorescences have both anti-oxidant and pro-oxidant effects, with the first being more pronounced than the latter. Some compounds prevent deoxyribose damage in this assay, not by reacting with hydroxyl radicals, but because they present ion-binding capacity and can withdraw the iron ions rendering them inactive or poorly active in Fenton reactions (Valentão et al., 2002). The assay performed in the absence of EDTA showed that the three Brassica varieties have some capacity to chelate iron ions, being $B$. oleracea var. acephala the most effective (Fig. 6).

The oxidizing properties of $\mathrm{HOCl}$ induce the conversion of TNB to DTNB, which is inhibited by a $\mathrm{HOCl}$ scavenger (Valentão et al., 2002). The analyzed inflorescences displayed protective activity against damage by $\mathrm{HOCl}$, which was concentration dependent. Among the distinct varieties $B$. oleracea var. costata and B. rapa var. rapa revealed to have higher scavenging ability, as shown in Fig. 7 and Table 4.

\subsection{Antimicrobial activity}

The aqueous extracts of the inflorescences were screened for their antimicrobial properties against B. cereus, B. subtilis, S. aureus, E. coli, P. aeruginosa, K. pneumoniae, C. albicans and C. neoformans. The minimal inhibitory concentration (MIC) values found for the tested bacteria and fungi (Table 5 ) were determined as an evaluation of the antimicrobial activity of the samples.

All the extracts presented antimicrobial capacity, inhibiting only Gram-positive bacteria and in the order $S$. aureus $>B$. cereus $>$ > . subtilis. Despite this, the response of each Brassica variety against the assayed microorganisms was different. B. rapa var. rapa revealed the highest activity against $B$. cereus, followed by $B$. oleracea var. costata and B. oleracea var. acephala. Only B. rapa var. rapa and $B$. oleracea var. costata showed some activity against $B$. subtilis. $S$. aureus was the most susceptible microorganism, presenting

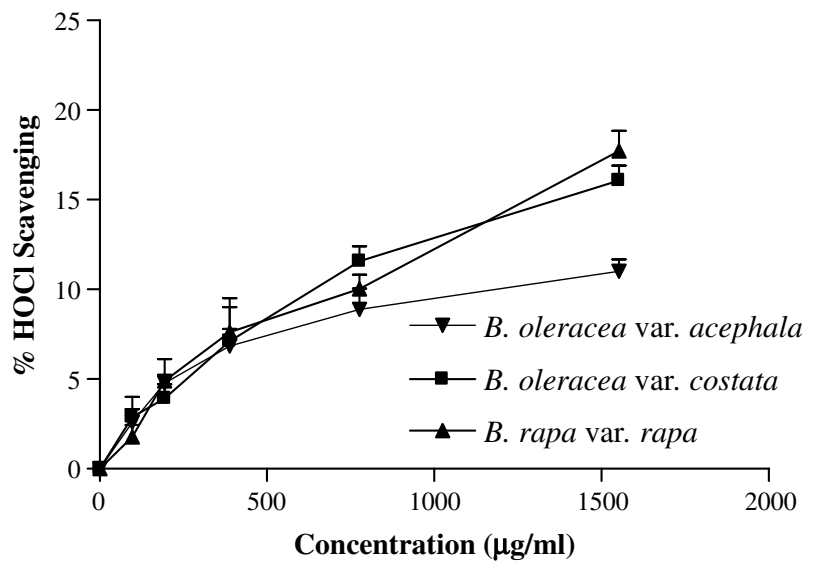

Fig. 7. Effect of inflorescences aqueous lyophilized extracts on the oxidation of TNB by $\mathrm{HOCl}$. Values show mean \pm SE from three experiments performed in triplicate. 
Table 5

Antimicrobial activity of the inflorescences' aqueous extracts ${ }^{\mathrm{a}}$

\begin{tabular}{|c|c|c|c|c|c|c|c|c|}
\hline \multirow[t]{2}{*}{ Samples } & \multicolumn{8}{|c|}{$\mathrm{MIC}(\mathrm{mg} / \mathrm{ml})$} \\
\hline & B. cereus & B. subtilis & S. aureus & P. aeruginosa & E. coli & K. peumoniae & C. albicans & C. neoformans \\
\hline B. rapa & 0.1 & 10.0 & 0.1 & 50.0 & 50.0 & 50.0 & 50.0 & 50.0 \\
\hline var. rapa & $(+++)$ & $(+)$ & $(+++)$ & $(-)$ & $(-)$ & $(-)$ & $(-)$ & $(-)$ \\
\hline B. oleracea & 0.1 & 10.0 & 0.1 & 50.0 & 50.0 & 50.0 & 50.0 & 50.0 \\
\hline var. costata & $(++)$ & $(+)$ & $(++++)$ & $(-)$ & $(-)$ & $(-)$ & $(-)$ & $(-)$ \\
\hline B. oleracea & 0.1 & 50.0 & 0.1 & 50.0 & 50.0 & 50.0 & 50.0 & 50.0 \\
\hline var. acephala & $(+)$ & $(-)$ & $(+++)$ & $(-)$ & $(-)$ & $(-)$ & $(-)$ & $(-)$ \\
\hline
\end{tabular}

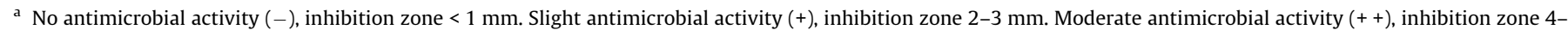
$5 \mathrm{~mm}$. High antimicrobial activity $(+++)$, inhibition zone $6-9 \mathrm{~mm}$. Strong antimicrobial activity $(++++)$, inhibition zone $>9 \mathrm{~mm}$. Standard deviation $\pm 0.5 \mathrm{~mm}$.

MICs of $0.1 \mathrm{mg} / \mathrm{ml}$ for the three inflorescences tested, with $B$. oleracea var. costata displaying the best antimicrobial capacity (Table 5). The tested Gram-negative bacteria (E. coli, $P$. aeruginosa and $K$. peumoniae) and fungi (C. albicans and $C$. neoformans) species were resistant to the inflorescences extracts (Table 5).

The chemical composition of the analyzed extracts can obviously be very complex and may contain several classes of hydrophilic compounds, besides the phenolics and organic acids indicated above. Consequently, it seems important to evaluate the activity of the inflorescences aqueous lyophilized extracts as a whole, because interactions may occur among the different compounds present. Although no correlation was found between the phenolics or organic acids contents and the observed activities, the detected compounds are, most probably, contributing to them. In fact, hydroxycinnamic acids and their derivatives (Fukumoto \& Mazza, 2000; Plumb, Price, Rhodes, \& Williamson, 1997), flavonol glycosides, including acylated derivatives (Braca et al., 2003; Tang, Lou, Wang, Li, \& Zhuang, 2001), or organic acids (Madhavi, Singhal, \& Kulkarni, 1996; Silva et al., 2004) have been reported to possess antioxidative properties, assessed in different systems. Additionally, the antimicrobial capacity of these phytochemicals against several microorganisms was also demonstrated before (Alakomi et al., 2007; Binutu, Adesogan, \& Okogun, 1996; Bloor, 1995; Lee, Thrupp, Owens, Cesario, \& Shanbrom, 2001; Mokbel \& Suganuma, 2006; Ou \& Kwok, 2004; Pomilio, Buschi, Tomes, \& Viale, 1992; Rigano et al., 2007). The obtained results are important, considering that the studied reactive oxygen species are produced in the organism or come from exogenous sources, being involved in several diseases (Aruoma, Halliwell, Hoey, \& Butler, 1989; Bast, Haenen, \& Doelman, 1991; Halliwell, 1991; Halliwell, Aeschbach, Löliger, \& Aruoma, 1995; Puppo, 1992). Furthermore, the dietary intake of these inflorescences may lower the risk of bacterial infections, namely of the gastrointestinal tract, being also useful in food industry as preservative (Frazier \& Westhoff, 1988).

In conclusion, the work herein indicates that the inflorescences of the three analyzed Brassica varieties are an appreciable source of protective compounds, like phenolics and organic acids. In addition, it points to the need of a diverse diet to get the most complete protection, through overlapping or complementary effects, as it is not possible to suggest one variety as being the best in terms of antioxidant or antimicrobial capacity.

\section{Acknowledgements}

The authors are grateful to Fundação para a Ciência e a Tecnologia (PTDC/AGR-AAM/64150/2006) for financial support of this work.

\section{References}

Alakomi, H.-L., Puupponen-Pimiä, R., Aura, A.-M., Helander, I. M., Nohynek, L., Oksman-Caldentey, K.-M., et al. (2007). Weakening of Salmonella with selected microbial metabolites of berry-derived phenolic compounds and organic acids. Journal of Agricultural and Food Chemistry, 55, 3905-3912.
Aruoma, O. I., Halliwell, B., Hoey, B. M., \& Butler, J. (1989). The antioxidant action of $n$-acetylcysteine: its reaction with hydrogen peroxide, hydroxyl radical, superoxide, and hypochlorous acid. Free Radical Biology \& Medicine, 6, 593-597.

Ayaz, F. A., Glew, R. H., Millson, M., Huang, H. S., Chaung, L. T., Sanz, C., et al. (2006). Nutrient contents of kale (Brassica oleracea L. var. acephala DC.). Food Chemistry, 99, 572-579.

Bast, A., Haenen, G. R. M. M., \& Doelman, C. J. A. (1991). Oxidants and antioxidants: State of the art. The American Journal of Medicine, 91(Suppl. 3C), 2S-13S.

Binutu, O. A., Adesogan, K. E., \& Okogun, J. E. (1996). Antibacterial and antifungal compounds from Kigelia pinnata. Planta Medica, 62, 352-353.

Bloor, S. J. (1995). An antimicrobial kaempferol-diacyl-rhamnoside from Pentachondra pumila. Phytochemistry, 38, 1033-1035.

Braca, A., Fico, G., Morelli, I., De Simone, F., Tomè, F., \& De Tommasi, N. (2003) Antioxidant and free radical scavenging activity of flavonol glycosides from different Aconitum species. Journal of Ethnopharmacology, 86, 63-67.

Cowan, M. M. (1999). Plant products as antimicrobial agents. Clinical Microbiology Reviews, 12, 564-582.

Fernandes, F., Valentão, P., Sousa, C., Pereira, J. A., Seabra, R. M., \& Andrade, P. B. (2007). Chemical and antioxidative assessment of dietary turnip (Brassica rapa var. rapa L.). Food Chemistry, 105, 1003-1010.

Ferreres, F., Sousa, C., Valentão, P., Seabra, R. M., Pereira, J. A., \& Andrade, P. B. (2007) Tronchuda cabbage (Brassica oleraceae L. var. costata DC) seeds: Phytochemical characterization and antioxidant potential. Food Chemistry, 101, 549-558.

Ferreres, F., Sousa, C., Vrchovská, V., Valentão, P., Pereira, J. A., Seabra, R. M., et al (2006). Chemical composition and antioxidant activity of tronchuda cabbage internal leaves. European Food Research \& Technology, 222, 88-98.

Ferreres, F., Valentão, P., Llorach, R., Pinheiro, C., Cardoso, L., Pereira, J. A., et al. (2005). Phenolic compounds in external leaves of tronchuda cabbage (Brassica oleraceae L. var. costata DC). Journal of Agricultural and Food Chemistry, 53, 2901-2907.

Frazier, W. C., \& Westhoff, D. C. (1988). Food-borne illness: Bacterial. E. Dollinger, Food Microbiology (4th ed., pp. 401-439). Singapore: McGraw-Hill.

Fukumoto, L. R., \& Mazza, G. (2000). Assessing antioxidant and prooxidant activities of phenolic compounds. Journal of Agricultural and Food Chemistry, 48, 3597-3604.

Halliwell, B. (1991). Reactive oxygen species in living systems: Source, biochemistry and role in human disease. The American Journal of Medicine, 91(Suppl. 3C), $14 \mathrm{~S}-22 \mathrm{~S}$.

Halliwell, B., Aeschbach, R., Löliger, J., \& Aruoma, O. I. (1995). The characterization of antioxidants. Food and Chemical Toxicology, 33, 601-617.

Hawkey, P.M., \& Lewis, D.A. (1994). Medical bacteriology - A practical approach (pp. 181-194). Oxford: Oxford University Press.

Heimler, D., Vignolini, P., Dini, M. G., Vincieri, F. F., \& Romani, A. (2006). Antiradical activity and polyphenol composition of local Brassicaceae edible varieties. Food Chemistry, 99, 464-469.

Lee, Y.-L., Thrupp, L., Owens, J., Cesario, T., \& Shanbrom, E. (2001). Bacterial activity of citrate against Gram-positive cocci. Letters in Applied Microbiology, 33, 349-351.

Liang, Y.-S., Kim, H. K., Lefeber, A. W. M., Erkelens, C., Choi, Y. H., \& Verpoorte, R. (2006). Identification of phenylpropanoids in methyl jasmonate treated Brassica rapa leaves using two-dimensional nuclear magnetic resonance spectroscopy. Journal of Chromatography A, 1112, 148-155.

Liu, R. H. (2003). Health benefits of fruit and vegetables are from additive and synergistic combinations of phytochemicals. American Journal of Clinical Nutrition, 78, 517S-520S.

Llorach, R., Gil-Izquierdo, A., Ferreres, F., \& Tomás-Barberán, F. A. (2003). HPLCDAD-MS/MS-ESI characterization of unusual highly glycosylated acylated flavonoids from cauliflower (Brassica oleracea L. var. botrytis) agroindustrial byproducts. Journal of Agricultural and Food Chemistry, 51, 3895-3899.

Madhavi, D. L., Singhal, R. S., \& Kulkarni, P. R. (1996). Natural antioxidants. In D. L. Madhavi, S. S. Deshpande, \& D. K. Salunkhe (Eds.), Food antioxidants Technological, toxicological and health perspectives (pp. 73-76). New York: Marcel Dekker.

Mokbel, M. S., \& Suganuma, T. (2006). Antioxidant and antimicrobial activities of the methanol extracts from pummelo (Citrus grandis Osbeck) fruit albedo tissues. European Food Research E' Technology, 224, 39-47.

Ou, S., \& Kwok, K.-C. (2004). Ferulic acid: Pharmaceutical functions, preparation and applications in foods. Journal of the Science of Food and Agriculture, 84, 1261-1269. 
Pereira, J. A., Pereira, A. P. G., Ferreira, I. C. F. R., Valentão, P., Andrade, P. B., Seabra, R., et al. (2006). Table olives from Portugal: Phenolic compounds, antioxidant potential and antimicrobial activity. Journal of Agricultural and Food Chemistry, 54, 8425-8431.

Plumb, G. W., Price, K. R., Rhodes, M. J., \& Williamson, G. (1997). Antioxidant properties of the major polyphenolic compounds in broccoli. Free Radical Research, 27, 429-435.

Podsędek, A. (2007). Natural antioxidants and antioxidant capacity of Brassica vegetables: A review. LWT - Science and Technology, 40, 1-11.

Pomilio, A. B., Buschi, C. A., Tomes, C. N., \& Viale, A. A. (1992). Antimicrobial constituents of Gomphrena martiana and Gomphrena boliviana. Journal of Ethnopharmacology, 36, 155-161.

Pulido, R., Bravo, L., \& Saura-Calixto, F. (2000). Antioxidant activity of dietary polyphenols as determined by a modified ferric reducing/ antioxidant power assay. Journal of Agricultural and Food Chemistry, 48 3396-3402.

Puppo, A. (1992). Effect of flavonoids on hydroxyl radical formation by Fenton-type reactions: Influence of the iron chelator. Phytochemistry, 31, 85-88.

Rigano, D., Formisano, C., Basile, A., Lavitola, A., Senatore, F., Rosselli, S., et al. (2007) Antibacterial activity of flavonoids and phenylpropanoids from Marrubium globosum ssp. Libanoticum. Phytotherapy Research, 21, 395-397.

Romani, A., Pinelli, P., Galardi, C., Corti, G., Agnelli, A., \& Heimler, D. (2003). Analysis of flavonoids in leaves of black cabbage (Brassica oleracea var. acephala DC subvar. viridis forma serotina) grown on different soils and heights. Italian Journal of Food Science, 15, 197-205.

Romani, A., Vignolini, P., Isolani, L., Ieri, F., \& Heimler, D. (2006). HPLC-DAD/MS characterization of flavonoids and hydroxycinnamic derivatives in turnip tops (Brassica rapa L. Subsp. sylvestris L.). Journal of Agricultural and Food Chemistry, $54,1342-1346$

Silva, B. M., Andrade, P. B., Valentão, P., Ferreres, F., Seabra, R. M., \& Ferreira, M. A (2004). Quince (Cydonia oblonga Miller) fruit (pulp, peel and seed) and jam: Antioxidant activity. Journal of Agricultural and Food Chemistry, 52, 4705-4712.
Sousa, A., Ferreira, I. C. F. R., Calhelha, R., Andrade, P. B., Valentão, P., Seabra, R., et al. (2006). Phenolics and antimicrobial activity of traditional stoned table olives "alcaparra". Bioorganic \& Medicinal Chemistry, 14, 8533-8538.

Sousa, C., Valentão, P., Rangel, J., Lopes, G., Pereira, J. A., Ferreres, F., et al. (2005). Influence of two fertilization regimens on the amounts of organic acids and phenolic compounds of tronchuda cabbage (Brassica oleraceae $\mathrm{L}$. var. costata DC). Journal of Agricultural and Food Chemistry, 53, 9128-9132.

Tang, Y., Lou, F., Wang, J., Li, Y., \& Zhuang, S. (2001). Coumaroyl flavonol glycosides from the leaves of Ginkgo biloba. Phytochemistry, 58, 1251-1256.

Tim Cushnie, T. P., \& Lamb, A. J. (2005). Antimicrobial activity of flavonoids. International Journal of Antimicrobial Agents, 26, 343-356.

Valentão, P., Fernandes, E., Carvalho, F., Andrade, P. B., Seabra, R. M., \& Bastos, M. L. (2001). Antioxidant activity of Centaurium erythraea infusion evidenced by its superoxide radical scavenging and xanthine oxidase inhibitory activity. Journal of Agricultural and Food Chemistry, 49, 3476-3479.

Valentão, P., Fernandes, E., Carvalho, F., Andrade, P. B., Seabra, R. M., \& Bastos, M. L. (2002). Antioxidative properties of cardoon (Cynara cardunculus L.) infusion against superoxide radical, hydroxyl radical and hypochlorous acid. Journal of Agricultural and Food Chemistry, 50, 4989-4993.

Vallejo, F., Tomás-Barberán, F. A., \& Ferreres, F. (2004). Characterization of flavonols in broccoli (Brassica oleracea L. var. italica) by liquid chromatography-UV diodearray detection-lectrospray ionisation mass spectrometry. Journal of Chromatography A, 1054, 181-193.

Vaughan, J. G., \& Geissler, C. A. (1997). The New Oxford Book of Food Plants. New York: Oxford University Press. p. 196.

Vrchovská, V., Sousa, C., Valentão, P., Ferreres, F., Pereira, J. A., Seabra, R. M., et al. (2006). Antioxidative properties of tronchuda cabbage (Brassica oleraceae L. var. costata DC) external leaves against DPPH, superoxide radical, hydroxyl radical and hypochlorous acid. Food Chemistry, 98, 416-425. 